\title{
Valor diagnóstico del examen citológico en las otitis externas de caninos
}

\author{
Boehringer, S.I. \\ Cátedra de Microbiología, Facultad de Ciencias Veterinarias, UNNE, Sargento Cabral 2139, Corrientes (3400), \\ Argentina, Tel: 03783-425357, E-mail: sboehringerklusas@yahoo.com.ar
}

\begin{abstract}
Resumen
Boehringer, S.I.: Valor diagnóstico del examen citológico en las otitis externas de caninos. Rev. vet. 22: 1, 38-42, 2011. Las levaduras del género Malassezia son organismos lipofílicos, comensales de la piel del hombre y los animales. Frecuentemente se la aísla como uno de los microorganismos más comunes de las otitis externas y a la vez uno de sus principales factores perpetuantes. El propósito del presente estudio consistió en evaluar la eficiencia del examen citológico como metodología diagnóstica, en otitis externas de caninos en la ciudad de Corrientes (Argentina). A tal fin se tomaron 95 muestras de perros con síntomas clínicos de otitis externa y de 95 perros sanos. Los exudados óticos se recolectaron con hisopos estériles y medio de transporte. Las muestras fueron sembradas en agar Sabouraud y agar Dixon modificado. Para detectar la presencia y cantidad de levaduras en las muestras procesadas se efectuó el examen citológico utilizando la tinción de Gram Kopeloff, observando 10 campos con objetivo de inmersión (1000x). El aislamiento de Malassezia pachydermatis en animales con otitis, $70,52 \%$ cultivos positivos, y sin otitis, $28,42 \%$ fue significativo $(p<0,05)$. La relación entre la citología y el aislamiento de la levadura, también fue significativo. La sensibilidad para la prueba citológica fue del $75,79 \%$, la especificidad del $50,53 \%$, arrojando un valor predictivo del $60 \%$; mientras que para el cultivo fueron del 70,53\%; 71,58\% y 70\%, respectivamente. La citología de los exudados óticos determina el sobrecrecimiento de Malassezia. Los resultados indicaron que los recuentos $\geq 10$ levaduras por campo de inmersión permite establecer el carácter microbiológico del proceso. Sin embargo considerando la sensibilidad de la prueba y la baja especificidad obtenida, atribuible a la desigual distribución de la levadura observada en la población sana, es necesario el empleo de dos o más técnicas simultáneas que permitan detectar Malassezia, determinar la importancia médica y verificar la infección.
\end{abstract}

Palabras clave: perro, Malassezia, otitis externa, canal auricular, análisis citólogico.

\begin{abstract}
Boehringer, S.I.: Diagnostic value of the cytological exam in canine otitis externa. Rev. vet. 22: 1, 38-42, 2011. Malassezia are lipophilic yeast, commensal organisms of human and animal skin. The yeast has often been isolated from otitis externa cases as the most common organism and complicating factor. The purpose of this study was to evaluate the effectiveness of cytology as a diagnostic methodology in canine external otitis in Corrientes City (Argentina). Samples from the auditory tube of 95 dogs with otitis and from 95 healthy dogs were obtained. Sterile cotton swabs were used to collect specimens from the external ear canal and then cultured in agar Sabouraud and modified Dixon's agar. Cytological examinations were performed to detect the presence and population size of Malassezia yeast. Each swab was rolled on a clean glass slide and stained with Gram Kopeloff. Ten fields were examined microscopically using an oil immersion objective (1000x magnification). The isolation of M. pachydermatis in dogs with external otitis $(70.52 \%)$, in relation to the healthy animals $(28.42 \%)$ was significant $(\mathrm{p}<0.05)$. The agreement between cytological results and fungal cultures were also statistically significant. The performance of the cytological examination and the culture showed a sensitivity around $75.79 \%$ and $70.53 \%$; specificity was $50.53 \%$ and $71.58 \%$; whereas predictive values were $60 \%$ and $70 \%$, respectively. Cytological examination of otic exudate confirms Malassezia overgrowth. In the present investigation the results indicated that $\geq 10$ yeast count per high-power fields (oil immersion objective) allows to identify and characterize the microbial infection. Nevertheless, considering the test sensitivity and low specificity obtained attributable to the unequal distribution of yeast observed in the healthy population, it is necessary to use two or more simultaneous techniques to detect Malassezia, determine the medical significance, and confirm infection.
\end{abstract}

Key words: dog, Malassezia, ear canal, otitis externa, cytological analysis. 


\section{INTRODUCCIÓN}

Los hongos mantienen diferentes categorías de asociaciones con los animales domésticos y los aislados, son por lo general, integrantes de la flora normal que recubre al hospedador. Levaduras como Candida, Trichosporon y Malassezia son conocidos por ser esencialmente saprobios. El género Malassezia comprende un grupo de basidiomycetos muy especializados dentro del que se encuentran especies que únicamente crecen en el laboratorio en medios especiales suplementados con lípidos. Han sido los caracteres genómicos los que definieron y continúan definiendo la taxonomía del género Malassezia, aunque se las sigue separando en dos grupos de acuerdo a su principal carácter taxonómico: las lipodependientes, trece especies reconocidas hasta el momento, y la única lipofílica no lipodependiente, Malassezia pachydermatis ${ }^{27}$.

Esta levadura es un comensal obligado de la piel y el conducto auditivo externo de los mamíferos, especialmente carnívoros, y es la que con más frecuencia se aísla de caninos, aunque se han reportado hallazgos de especies lipodependientes como M. furfur, M. globosa y M. sympodialis tanto en animales sanos como enfermos. En determinadas circunstancias relacionadas a cambios en el estado ecológico o de los mecanismos inmunológicos de su hospedador, que regulan la colonización, pueden proliferar causando enfermedad (seborrea, atopias, dermatitis alérgicas, otitis y otras) ${ }^{19}$.

El conducto auditivo externo representa un ambiente frágil donde los cambios inflamatorios son capaces de producir un desbalance en el equilibrio de su microbiota, convirtiéndose M. pachydermatis en uno de los factores perpetuantes más frecuentemente observados en perros. Existen situaciones en las que los aislamientos pueden resultar ambiguos y es necesario el empleo de varias técnicas (culturales, citológicas) para detectar Malassezia, sin embargo la presencia de un hongo debe estar asociada a la correcta evaluación del status o sea de la situación en su conjunto, para poder determinar la importancia médica del significado del cultivo.

El propósito del presente estudio consistió en demostrar la eficiencia del examen citológico a la hora de definir el estado de patógeno oportunista de la levadura M. pachydermatis en otitis externas de caninos.

\section{MATERIAL Y MÉTODOS}

Animales. Se obtuvieron muestras de perros atendidos en clínicas privadas y en el Hospital de Clínicas de la Facultad de Ciencias Veterinarias de Corrientes (Argentina). Para su estudio, la población muestreada se dividió en dos grupos. Los animales enfermos fueron 95 caninos con diagnóstico clínico de otitis externa uni o bilateral que asistieron a la consulta presentando todos o algunos de los siguientes síntomas: prurito, rubor, congestión e inflamación del canal auditivo externo, descarga purulenta o excesivo cerumen ${ }^{16}$, los cuales no habían recibido ningún tipo de tratamiento tópico o sistémico previo a la toma de muestra. Los perros de este grupo fueron tanto animales de raza como cruzas, 46 hembras y 49 machos, entre 2 meses y 15 años de edad ( $45 \%$ de los caninos entre 1 a 5 años) y una media de 4 años. Los animales testigos fueron 95 caninos que asistieron a la consulta veterinaria por otros motivos y no manifestaron ningún síntoma de otitis externa. Los perros de este grupo también fueron animales de raza y cruzas, 47 hembras y 48 machos, con una edad comprendida entre los 2 meses y 15 años ( $52 \%$ de los caninos entre 1 y 5 años de edad) y una media de 3 años.

Muestras. Los exudados óticos se recolectaron al comienzo del examen otoscópico con hisopos de algodón estériles, traccionando suavemente el pabellón en dirección ventral, introduciendo el hisopo dentro del meato auditivo externo y haciéndolo rotar durante cinco segundos contra sus paredes ${ }^{3,7,10,12,30}$. Luego fueron colocados en medio de transporte de Stuart (Eurotubo® Deltalab, España), y remitidos al laboratorio para su procesamiento. El empleo de hisopos estériles en el muestreo es considerada la técnica más recomendable debido a que es fácil de utilizar y además porque sirve tanto para el examen citológico como para el cultivo ${ }^{7}$. En todos los casos la muestra se tomó de un solo oído por perro ${ }^{16}$. En los caninos es posible la recuperación simultánea de Malassezia a partir de ambos oídos existiendo una doble vía de contaminación debido al rascado ${ }^{23}$.

Examen citológico. Con los hisopos de las muestras obtenidas se realizaron extendidos sobre portaobjetos de vidrio, los que se fijaron al calor ${ }^{16,30} \mathrm{y}$ fueron coloreados con la tinción de Gram modificada por Kopeloff, alcalinizado al colorante primario con bicarbonato de sodio y empleando como mordiente lugol débil. La observación microscópica de las levaduras y las células epiteliales se realizó en diez campos empleando objetivo de inmersión (1000x $)^{21}$. El conteo de levaduras observadas por campo se clasificó en abundante ( $>$ de 10), regular (6 a 10) y escaso (1 a 5); para las células epiteliales se utilizó un sistema similar con los siguientes valores: abundante ( $\geq$ de 5), regular (3 a 4) y escaso (1 a 2 ).

Cultivo micológico. Las muestras fueron inoculadas, para un primer aislamiento, en agar Dixon modificado por Midgley: $5 \%$ extracto de malta, $1 \%$ peptona, $2 \%$ bilis desecada, $1 \%$ tween $40,0,2 \%$ glicerol, $2 \%$ agar $\mathrm{pH} 6,0^{2}$ y agar Sabouraud dextrosa modificado por Emmons con antibiótico: $2 \%$ dextrosa, 1\% peptona, $1,7 \%$ agar agar, cloranfenicol en concentración final de $100 \mathrm{ug} / \mathrm{ml}, \mathrm{pH}$ 6,8-7,0. Las siembras se realizaron en forma directa estriando los hisopos en placas de Petri de $9 \mathrm{~cm}$, se incubaron aeróbicamente en estufa a 32 y $35^{\circ} \mathrm{C}$, respectivamente durante 7 días y se monitorearon diariamente $4,5,9,11,17,18,24$

La caracterización de la levadura $M$. pachydermatis se realizó a partir de su macromorfología (colonias pequeñas, lisas, de bordes circulares, semiduras, com- 
pactas y adheridas al agar, de color blanco a beige, que se tornan marrón con el tiempo); por su habilidad de crecer en un subcultivo realizado en medio Sabouraud sin suplementación lipídica (de las colonias obtenidas en medio Dixon modificado, 5-8 colonias por muestra fueron sembradas en agar Sabouraud) ${ }^{15,23}$ y por su morfología microscópica (levadura oval pequeña con blastosporos unipolares, sin tubos germinativos, hifas o pseudohifas).

Análisis estadístico. Para la descripción de las variables se utilizaron parámetros descriptivos como medias, frecuencias, porcentajes, proporciones. Los datos obtenidos fueron analizados a través de pruebas de significancia: utilizando el Chi-cuadrado a partir de tablas de contingencia de $2 \times 2$ y $2 \times 4$. Un valor de $p<0,05$ fue considerado significativo. Los intervalos de confianza se establecieron en $95 \%$. Se realizaron pruebas de asociación: riesgo relativo y odd ratio. En las técnicas diagnósticas, la sensibilidad y la especificidad del examen citológico fueron calculadas en base a los resultados obtenidos en los cultivos micológicos. Además se determinó, valor predictivo positivo y concordancia. El software utilizado fue Infostat versión 2008, licencia de la Cátedra de Cálculo Estadístico de la Facultad de Ciencias Agrarias de la UNNE y el Epidat (3.1 OPS/ OMS), licencia de la Cátedra de Salud Pública, Facultad de Ciencias Veterinarias, UNNE.

\section{RESULTADOS Y DISCUSIÓN}

Sobre un total de 95 muestras de perros con otitis externa se obtuvieron: 67 (70,53\%) cultivos con aislamiento de $M$. pachydermatis mientras que los resultados de los exámenes de laboratorio obtenidos en la población testigo dieron $27(28,4 \%)$ cultivos positivos. El aislamiento fue significativo $(p=0,0000)$ al comparar ambas poblaciones de animales.

La observación microscópica directa de las muestras utilizando la coloración de Gram-Kopeloff, reveló la presencia de células redondeadas a oblongas, estas últimas predominantes. En el estudio citológico de la población enferma se observaron 72 (75,8\%) extendidos positivos a Malassezia, de los cuales 64 muestras $(67,38 \%)$ resultaron con aislamiento de la levadura y 8 $(8,42 \%)$ sin aislamiento en los cultivos micológicos. Se obtuvieron 3 cultivos $(3,15 \%)$ con citología negativa y fueron coincidentes (observación negativa y cultivo sin desarrollo) 20 casos $(21,05 \%)$ (Tabla 1). El examen microscópico directo de los 95 exudados óticos de la población testigo dio como resultado $48(50,52 \%)$ observaciones negativas de levaduras, 47 (49,48\%) positivas y dentro de éstas $6(6,32 \%)$ con abundantes células (Tabla 1).

Relacionando en la observación microscópica directa la cantidad de levaduras (de todas las especies) y células epiteliales, de los 72 preparados provenientes de perros con otitis y positivos a la citología, se obtuvieron $28(38,9 \%)$ casos en donde se observaron abundantes levaduras y células, simultáneamente y 20
$(27,8 \%)$ muestras con escasos elementos de ambas. La población testigo, con 49 extendidos positivos, arrojó un resultado de 1 preparado $(2,13 \%)$ con una relación abundante entre estas células y 28 observaciones $(59,57 \%)$ escasas de las dos (Tabla 2).

La citología brinda información diagnóstica sobre el número y tipo de agentes infecciosos y células inflamatorias. Cuando se realiza el examen microscópico de las muestras del conducto auditivo de animales sin otitis puede observarse la presencia de células epiteliales y un número bajo de comensales integrantes normales de la microbiota, que no dejan de ser patógenos potenciales. Para algunos autores la observación ocasional de alguna levadura o bacteria en campo de inmersión debe ser considerada normal. Las células epiteliales escamosas son largas, angulares, aisladas, con núcleo ausente o picnótico y abundante citoplasma. Se encuentran en los frotis de perros sanos, pero en aquellos con otitis pueden observarse en grandes cantidades ${ }^{29}$. Es decir, al realizar la observación microscópica, básicamente existen tres elementos que nos permitirían evaluar la condición del conducto auditivo externo de los caninos: los microorganismos (bacterias y levaduras), las células del sistema inmune y las células epiteliales.

Los exámenes realizados demostraron la presencia de abundantes levaduras en la población enferma, la relación entre la citología y el aislamiento de la levadura fue altamente significativa $(\mathrm{p}=0,0000)$. Aunque algunos autores han sugerido que 2 ó 3 células de $M a-$ lassezia por paquete de células epiteliales es anormal, la mayoría de los reportes coincide en la propuesta de considerar a Malassezia un agente etiológico del proceso infeccioso cuando más de 10 levaduras por campo de inmersión son encontradas en la observación microscópica del exudado ótico $^{7,14,15,29}$. Puede afirmarse que la citología de los exudados óticos determina el sobrecrecimiento de Malassezia. Los resultados hallados indicaron que los recuentos $\geq 10$ levaduras por campo de inmersión permiten establecer el carácter microbiológico del proceso. Un número muy escaso de preparados de ambas poblaciones, ocho en total, dio como resultado una citología negativa, circunstancia atribuible al elemento empleado para muestrear ${ }^{16}$.

Utilizando al cultivo como prueba diagnóstica de referencia, los valores obtenidos para el examen citológico en este estudio fueron bajos (especificidad 50,53\% y valor predictivo $60,50 \%$ ), contrastando con los valores reportados por otros autores (95\% de especificidad y $87 \%$ de valor predictivo) ${ }^{14}$. Sin embargo, la sensibilidad $(75,79 \%)$ resultó superior a la del 30\% registrada en otras investigaciones ${ }^{7}$. El valor predictivo positivo, que se interpreta como la probabilidad de que un individuo haya estado realmente enfermo ante un resultado positivo a la prueba diagnóstica, fue inferior en la citología $(60,50 \%)$ que en el cultivo (71,28\%). La sensibilidad del cultivo alcanzó el 70,53\% y la especificidad 71,58\%.

La concordancia observada, que mide el grado de acuerdo entre dos pruebas diagnósticas fue buena $(0,78)$. El valor K (kappa), que corrige la intervención 
Tabla 1. Relación entre la microscopia directa y los aislamientos de M. pachydermatis en perros con y sin otitis.

\begin{tabular}{lcccccc}
\hline & \multicolumn{5}{c}{ aislamiento de M. pachydermatis } \\
\cline { 2 - 6 } OMD & $\mathrm{P}(\mathrm{n}, \%)$ & $\mathrm{N}(\mathrm{n}, \%)$ & $\mathrm{T}(\mathrm{n}, \%)$ & $\mathrm{P}(\mathrm{n}, \%)$ & $\mathrm{N}(\mathrm{n}, \%)$ & $\mathrm{T}(\mathrm{n}, \%)$ \\
\hline & $3(3,15)$ & $20(21,05)$ & $23(24,2)$ & $5(5,26)$ & $43(45,26)$ & $48(50,52)$ \\
& $13(13,68)$ & $7(7,37)$ & $20(21,05)$ & $10(10,53)$ & $24(25,26)$ & $34(35,79)$ \\
$1-5$ & $15(15,8)$ & $1(1,05)$ & $16(16,85)$ & $6(6,32)$ & $1(1,05)$ & $7(7,37)$ \\
$6-10$ & $36(37,9)$ & - & $36(37,9)$ & $6(6,32)$ & - & $6(6,32)$ \\
$>10$ & $67(70,53)$ & $28(29,47)$ & $95(100)$ & $27(28,43)$ & $68(71,57)$ & $95(100)$ \\
total & &
\end{tabular}

OMD: observación microscópica directa, P: positivos, N: negativos, T: total, n: número de muestras, \%: porcentaje.

Tabla 2. Relación entre células epiteliales y levaduras observadas al examen microscópico directo en perros con y sin otitis.

\begin{tabular}{lcccc}
\hline OMD cel. epit. & $\mathrm{A}(>10) \mathrm{n}, \%$ & $\mathrm{R}(6$ a 10$) \mathrm{n}, \%$ & $\mathrm{E}(1 \mathrm{a} 5) \mathrm{n}, \%$ & $\mathrm{~T}(\mathrm{n}, \%)$ \\
\hline perros con otitis & \multicolumn{5}{c}{} \\
\hline $\mathrm{A}(\geq 5)$ & $28(38,9)$ & $3(4,16)$ & - & $31(43,06)$ \\
$\mathrm{R}(3 \mathrm{a} 4)$ & $8(11,1)$ & $9(12,5)$ & - & $17(23,6)$ \\
$\mathrm{E}(1 \mathrm{a} 2)$ & - & $4(5,55)$ & $20(27,8)$ & $24(33,35)$ \\
$\mathrm{T}$ & $36(50)$ & $16(22,2)$ & $20(27,8)$ & $72(100)$ \\
\hline perros sin otitis & \multicolumn{5}{|c}{} \\
$\mathrm{A}(\geq 5)$ & $1(2,13)$ & - & $1(2,13)$ & $2(4,26)$ \\
$\mathrm{R}(3 \mathrm{a} 4)$ & $5(10,64)$ & $4(8,51)$ & $5(10,64)$ & $14(29,79)$ \\
$\mathrm{E}(1$ a 2$)$ & - & $3(6,38)$ & $28(59,57)$ & $31(65,95)$ \\
$\mathrm{T}$ & $6(12,77)$ & $7(14,89)$ & $34(72,34)$ & $47(100)$ \\
\hline
\end{tabular}

OMD cel. epit.: observación microscópica directa de células epiteliales, A: abundantes, R: regulares, E: escasas, T: total, n: número de muestras, \%: porcentaje.

del azar en la concordancia observada al incluir la concordancia esperada, fue de 0,56 lo cual indica un nivel de acuerdo moderado entre las dos pruebas estudiadas (los limites van de 0,40 a 0,50$)^{28}$. En este trabajo la prevalencia aparente, es decir la proporción de animales positivos a la prueba diagnóstica, fue del $49,47 \%$ para el cultivo y del $62,63 \%$ para la citología, mientras que la prevalencia real arrojó un valor del $50 \%$ en ambas pruebas. El hallazgo de estos resultados no es paradójico, si se consideran la complejidad, la etiología multifactorial de la patología, y fundamentalmente la desigual distribución del microorganismo en la población canina. En muchos casos de perros con otitis externa la cantidad de levaduras encontradas no es particularmente elevada, pudiendo ocurrir lo contrario en animales sanos, donde en ocasiones las levaduras aisladas alcanzan valores muy altos.

Otra estimación realizada a partir de la citología fue la relación entre las células epiteliales y las levaduras observadas. Para la categoría "abundantes células / abundantes levaduras", los valores obtenidos en los perros con otitis y sin otitis fueron del $38,88 \%$ y $2,12 \%$ respectivamente, indicando una aparente correspondencia entre la presencia de la levadura y las células epiteliales. Contrariamente, en otros trabajos no se encontraron diferencias significativas en el recuento de células epiteliales entre los animales sanos y enfermos ${ }^{14}$.

Una posible explicación al elevado número de células podría teorizarse a partir de la síntesis de fos- folipasa por $M$. pachydermatis. La fosfolipasa es una enzima producida por las cepas patógenas y es capaz de hidrolizar glicerofosfolípidos liberando ácidos grasos esenciales para el crecimiento del hongo. La exposición a la fosfolipasa producida por los microorganismos induce a la formación de poros en la membrana alterando todas las funciones celulares ${ }^{8}$. Diferentes estudios indicarían que estas enzimas tendrían otras funciones aparte del daño directo provocado a las células y que se comportan como potentes agentes inflamatorios $6,13,20$ Se ha observado que los aislamientos de $M$. pachydermatis provenientes de piel lesionada produjeron una elevada actividad fosfolipasa ${ }^{6}$. Por otro lado, diferentes estudios realizados en piel normal sugieren que Malassezia reduce la respuesta inflamatoria permitiéndole vivir como comensal, es decir que estas levaduras tienen la capacidad de modular la respuesta inmune cutánea en sus hospedadores ${ }^{1}$.

Cuando se trata de un microorganismo perteneciente a la microbiota y potencialmente patógeno es difícil encontrar un criterio riguroso, un método patrón o de referencia, es decir el stándar de oro (del inglés gold standard) que permita definir el estado de infección. Muchas veces es necesario el empleo de varias técnicas conjuntas (culturales, citológicas, histopatológicas) para detectar Malassezia ${ }^{25}$.

El análisis citológico de los exudados óticos puede utilizarse de rutina, es una técnica económica, simple y arroja resultados inmediatos que permiten verificar el carácter microbiológico de la infección y monitorear la respuesta a la terapia. Algunos autores lo consideran suficiente como para implementar el tratamiento de la otitis ${ }^{16,22}$.

Si bien los resultados obtenidos indican que los recuentos $\geq 10$ células de Malassezia por campo microscópico de inmersión podrían ser indicativos de la patogenicidad del microorganismo, debe tenerse en cuenta la sensibilidad de la prueba y la baja especificidad obtenida, atribuible a la desigual distribución de esta levadura en los diferentes individuos de la población canina sana. Por lo tanto, sería más correcto esperar los resul- 
tados de pruebas diagnósticas más concluyentes antes de realizar un tratamiento antifúngico. Coincidimos con autores ${ }^{26}$ que aseveran que antes que el examen microscópico, el cultivo fúngico debería usarse como diagnóstico definitivo para las otitis.

\section{REFERENCIAS}

1. Ashbee HR. 2006. Recent developments in the immunology and biology of Malassezia species. FEMS Immunol Med Microbiol 47: 14-23.

2. Bond R, Collin NS, Lloyd DH. 1994. Used of contact plates for the quantitative culture of Malassezia pachydermatis from canine skin. $J$ Small An Pract 35: 68-72.

3. Bond R, Saijonmaa LE, Lloyd DH. 1995. Population sizes and frequency of Malassezia pachydermatis at skin and mucosal sites on healthy dogs. J Small An Pract 36: 147-150.

4. Bond R, Lloyd DH. 1996. Comparison of media and conditions of incubation for the quantitative culture of $\mathrm{Mal}$ assezia pachydermatis from canine skin. Res Vet Sci 61: 273-274.

5. Canteros CE, Soria M, Rivas C, Lee W, López Joffre MC, Rodero L, Perrotta D, Körte C, Davel G. 2003. Especies de Malassezia aisladas de patologías de piel en un centro asistencial de la ciudad de Buenos Aires, Argentina. Rev Arg Microbiol 35: 156-161.

6. Cafarchia C, Otranto D. 2004. Association between phospholipase production by Malassezia pachydermatis and skin lesions. J Clin Microbiol 42: 4868-4869.

7. Cafarchia C, Gallo S, Romito D, Capelli G, Chermette R, Guillot J, Otranto D. 2005. Frequency, body distribution, and population size of Malassezia species in healthy dogs and in dogs with localized cutaneous lesions. J Vet Diagn Invest 17: 316-322.

8. Coutinho SD, Paula CR. 2000. Proteinase, phospholipase, hyaluronidase and chondroitin-sulphatase production by Malassezia pachydermatis. Med Micol 38: 73-76.

9. Crespo MJ, Abarca ML, Cabañes FJ. 2000. Atypical lipid-dependent Malassezia species isolated from dogs with otitis externa. J Clin Microbiol 38: 2383-2385.

10. Crespo MJ, Abarca ML, Cabañes FJ. 2002. Occurrence of Malassezia spp in horses and domestic ruminants. Mycoses 45: 333-337.

11. Gabal MA. 1988. Preliminary studies on the mechanism of infection and characterization of Malassezia pachydermatis in association with canine otitis externa. Mycopathología 104: 93-98.

12. Garau M, Del Palacio A, García J. 2005. Prevalence of Malassezia spp in healthy pigs. Mycoses 48: 17-20.

13. Ghannoum MA. 2000. Potential role of phospholipases in virulence and fungal pathogenesis. Clin Microbiol Rev 13: 122-143.

14. Ginel PJ, Lucena R, Rodríguez JC, Ortega J. 2002. A semiquantitative cytological evaluation of normal and pathological samples from the external ear canal of dogs and cats. Vet Dermatol 13: 151-156.
15. Girão MD, Prado MR, Brilhante RS, Cordeiro RA, Monteiro AJ, Sidrim JJ, Rocha MF. 2006. Malaseezia pachydermatis isolated from normal and diseased external ear canal in dogs: A comparative analysis. Vet J 172: 544-548.

16. Griffin JS, Scout WD, Erb HN. 2007. Malassezia otitis externa in the dog: The effect of heat-fixing otic exudate for cytological analysis. J Vet Med Ass 54: 424-427.

17. Guillot J, Guého E, Lesourd M, Midgley G, Chévrier G, Dupont B. 1996. Identification of Malassezia species. A practical approach. J Mycol Med 6: 103-110.

18. Guillot J, Breugnot C, Barros M, Chermette R. 1998. Usefulness of modified Dixon's medium for quantitative culture of Malassezia species from canine skin. J Vet Diagn Invest 10: 384-386.

19. Guillot J, Guého E, Mialot M, Chermette R. 1998. Importance des levures du genre Malassezia en dermatologie vétérinaire. Le Point Vet 29: 691-701.

20. Ivanovska N. 2003. Phospholipases as a factor of pathogenicity in microorganisms. $J$ Mol Catal B: Enzymatic 22: 357-361.

21. Kowalski JJ. 1988. The microbial environment of the ear canal in health and disease. Small An Pract 18: 743-754.

22. Martín JL, Tejedor MT, Lupiola P, Morales M, González Z. 2001. Relación entre la presencia de Malassezia pachydermatis y los signos clínicos encontrados en cuadros de otitis crónicas caninas en una población de perros de raza Podenco Canario. Clin Vet Peq Anim 21: 103-111.

23. Nardoni S, Dini M, Taccini F, Mancianti F. 2007. Occurrence, distribution and population size of Malassezia pachydermatis on skin and mucosae of atopic dogs. Vet Microbiol 122: 172-177.

24. Negroni R, Guelfand L. 1999. Manual de procedimientos para laboratorios de micología médica, Ed Acta Bioq Clín Lat (Suplem), La Plata (Argentina), 57 p.

25. Pérez J, Carrasco L. 2000. Diagnóstico histológico de micosis en patología veterinaria. Rev Iberoam Micol 17: S18-S22.

26. Prado MR, Brilhante RS, Cordeiro RA, Monteiro AJ, Sidrim JJ, Rocha MF. 2008. Frequency of yeast and dermatophytes from healthy and diseased dogs. $J$ Vet Diagn Invest 20: 197-202.

27. Summerbell RC. 2004. Fungi associated with vertebrates. In: Biodiversity of fungi (Mueller GM, Bills GF, Foster MS Ed), Elsevier Academic Press, Burlington (Massachusetts, USA), p. 451-465.

28. Tarabla HD. 2000. Epidemiología diagnóstica, Ed. Univ Nac Litoral, Santa Fe (Argentina), p. 37-79.

29. Thomas JS. 2005. Citología aplicada. Otitis externa. Clínica Práctica (Barcelona, España) 1: 28-30.

30. Toma S, Cornegliani L, Persico P, Noli C. 2006. Comparison of 4 fixation and staining methods for the cytologic evaluation of ear canals with clinical evidence of ceruminous otitis externa. Vet Clin Pathol 35: 194-198. 